\title{
Making FIT Count: Maximizing Appropriate Use of the Fecal Immunochemical Test for Colorectal Cancer Screening Programs
}

\author{
Vivy T. Cusumano, $\mathrm{MD}^{7}$ and Folasade P. May, MD, PhD, MPhil ${ }^{1,2,3,4}$
}

'Department of Medicine, David Geffen School of Medicine at UCLA, CA, Los Angeles, USA; ${ }^{2}$ Vatche and Tamar Manoukian Division of Digestive Diseases, Department of Medicine, David Geffen School of Medicine at UCLA, Los Angeles, CA, USA; ${ }^{3}$ UCLA Kaiser Permanente Center for Health Equity, UCLA Jonsson Comprehensive Cancer Center, CA, Los Angeles, USA; ${ }^{4}$ Department of Medicine, VA Greater Los Angeles Healthcare System, CA, Los Angeles, USA.

Colorectal cancer (CRC) remains one of the most common and deadly malignancies despite advancements in screening, diagnostic capabilities, and treatment. The ability to detect and remove precancerous and cancerous lesions via screening has altered the epidemiology of the disease, decreasing incidence, mortality, and late-stage disease presentation. The fecal immunochemical test (FIT) is a screening test that aims to detect human hemoglobin in the stool. FIT is the most common CRC screening modality worldwide and second most common in the United States. Its use in screening programs has been shown to increase screening uptake and improve CRC outcomes. However, FIT-based screening programs vary widely in quality and effectiveness. In health systems with high-quality FIT screening programs, only superior FIT formats are used, providers order FIT appropriately, annual patient participation is high, and diagnostic followup after an abnormal result is achieved in a timely manner. Proper utilization of FIT involves multiple steps beyond provider recommendation of the test. In this commentary, we aim to highlight ongoing challenges in FIT screening and suggest interventions to maximize FIT effectiveness. Through active engagement of patients and providers, health systems can use FIT to help optimize $\mathrm{CRC}$ screening rates and improve CRC outcomes.

KEY WORDS: colorectal cancer; screening; fecal immunochemical test; cancer detection; stool-based test.

$J$ Gen Intern Med 35(6): 1870-4

DOI: $10.1007 / \mathrm{s} 11606-020-05728-\mathrm{y}$

(c) Society of General Internal Medicine 2020

\section{INTRODUCTION}

In the United States (U.S.), colorectal cancer (CRC) is the 2nd leading cause of cancer-related deaths. ${ }^{1}$ Screening, which improves CRC outcomes by detecting precancerous and cancerous lesions early, has contributed substantially to the decline in CRC incidence and mortality over the past several

Received August 23, 2019

Accepted February 10, 2020

Published online March 3, 2020 decades. ${ }^{2-4}$ Despite the demonstrated benefits of screening, only $65 \%$ of age-eligible adults are up to date in the U.S. ${ }^{5,6}$

There are multiple stool-based and structural modalities for CRC screening. ${ }^{7,}{ }^{8}$ Of these, the fecal immunochemical test (FIT) is the most common CRC screening modality worldwide and the second most common in the U.S. ${ }^{9}$ Currently, the MultiSociety Task Force (MSTF) recommends FIT alongside colonoscopy as 1 of 2 first-tier CRC screening tests. ${ }^{10}$ FIT is an inexpensive, noninvasive, and convenient test that has resulted in higher screening participation than other modalities in many settings. $^{7}, 10-12$ The test characteristics are superior to stool guaiac tests (i.e. FOBT), with increased sensitivity to detect advanced adenomas and colorectal adenocarcinomas and the ability to reduce both CRC incidence and mortality. ${ }^{9,}{ }^{10}$ The question facing patients, providers, and health systems is no longer whether to use FIT but rather how to optimize its use.

Efficient and effective screening programs employ tests that are sensitive and specific while also assuring patient engagement, provider guidance, and health system tracking to optimize screening quality. ${ }^{10}$ Persistent issues in FIT screening include variability in available FIT formats, FIT administration and processing, timely diagnostic follow-up after abnormal FIT, and adherence to recurrent screening recommendations. ${ }^{10}$ We will review these ongoing challenges and suggest various strategies to maximize the benefits of FIT screening programs for health systems that wish to improve CRC screening and outcomes. Through active engagement from patients, providers, and health systems, FIT screening programs can be more effective in improving CRC screening and outcomes.

\section{Not All FIT Kits Are Created Equal}

There is a wide diversity of available FIT formats that vary in the number of stool samples recommended (1 vs. 3), analytic technique (qualitative vs. quantitative), optimal cut-off value for the amount of hemoglobin detected to define an abnormal result, and type of manufacturer devices. ${ }^{10,13,14}$ One-sample FIT regimens and multiple sample regimens have similar CRC sensitivity in meta-analysis, and organized CRC screening programs vary in the number of FIT samples recommended. ${ }^{15-17}$ Qualitative and quantitative FIT kits have similar 
performance; however, quantitative FIT kits allow users to adjust the abnormal cut-off limit to best target sensitivity for advanced neoplasia (e.g., increasing the cut-off value decreases sensitivity and increases specificity for $\mathrm{CRC}$ ) and take into consideration population-specific factors such as capacity for colonoscopy and cost-effectiveness. ${ }^{18-21}$ The MSTF recommends a cut-off value of $<20 \mathrm{gb} / \mathrm{g}$ feces based on evidence from meta-analyses that this cut-off offers the best combination of sensitivity, specificity, and diagnostic accuracy for $\mathrm{CRC}$, and is cost effective. ${ }^{22}$

There are currently over 65 FIT formats in circulation globally and 26 unique FIT kits on the market in the U.S., with variable test characteristics. ${ }^{13,}{ }^{23-26}$ The 2016 U.S. Preventive Services Task Force (USPSTF) guidelines recommend the OC FIT-CHEK products (OC-Light and OC-Auto) due to high test performance (sensitivity and specificity). ${ }^{27,}{ }^{28}$ Since this recommendation, however, new evidence has emerged that InSure FIT has higher sensitivity for advanced colorectal neoplasia $(26.3 \%, 95 \%$ CI $15.9-40.7)$ when compared with OC FIT-CHEK $\left(15.1 \%, 95 \%\right.$ CI 6.7-26.1) ${ }^{29}$ Health systems must consider FIT format characteristics and local resources when selecting the best FIT kit and assay cut-off value for their patient population. ${ }^{27}$

\section{Patients and Providers Must Know how to Use FIT Appropriately}

FIT screening success is determined by appropriate use of the test by providers, patients, and health systems. Providers play a key role in assuring appropriate prescribing of FIT, which should only be performed in the ambulatory setting and with spontaneously passed stools. ${ }^{21}$ The use of digital rectal examination to obtain a FIT stool sample is understudied; however, a clinical trial examining the efficacy of digital rectal exam for FIT is underway and may impact recommendations. ${ }^{30}$ Patients must be instructed on how to collect the stool sample properly and to return the sample to the laboratory for processing within the timeframe indicated by the FIT manufacturer. The manufacturer for OC-Sensor FIT (Polymedco Inc.), for example, recommends laboratory processing of the sample within 15 days of stool collection to avoid reduced test sensitivity. Two weeks after a sample has been collected, almost a third of abnormal results have the potential to convert to negative. ${ }^{31}$ Data also suggest that stool samples exposed to high ambient temperature have reduced sensitivity, which may impact screening outcomes. ${ }^{32}$

Inappropriate use of the test can also occur when patients who are not eligible for CRC screening (i.e due to age, life expectancy) are prescribed a FIT kit. Offering FIT to patients with multiple comorbidities or other factors precluding evaluation with colonoscopy if indicated may have the unintended consequences of worsening quality of care. ${ }^{22}$ Mailed FIT interventions that utilize system-level tools to target patients due for screening have been shown to improve FIT completion but should be used with caution as some patients require more personalized decision support. ${ }^{33}$ Another common practice that should be discouraged is repeating a FIT when the result is abnormal. Even if the repeat FIT is negative, a patient may have an advanced tubular adenoma or cancerous lesion that requires further evaluation with colonoscopy. ${ }^{10,}{ }^{34}$ Similarly, there are data to support that patients with an abnormal FIT result should be offered a repeat colonoscopy even in the setting of recent prior colonoscopy as poor colonic preparation and missed colonic lesions are common.$^{10,35}$ Providers should receive education about these common shortcomings of FIT administration. Health systems can help minimize inappropriate use of FIT by tracking inappropriate FIT prescribing, FIT processing errors, abnormal results, and repeat FIT orders. By identifying challenges in FIT administration processes, targeted interventions can be implemented to address deficiencies.

\section{Diagnostic Colonoscopy After Abnormal FIT Is Fundamental}

Lack of colonoscopic follow-up after abnormal FIT is associated with increased mortality from CRC and late-stage disease at diagnosis. ${ }^{36-38}$ However, colonoscopy rates after abnormal FIT are suboptimal across multiple health care systems in the U.S. ${ }^{39-43}$ Barriers to colonoscopic follow-up are broad and include patient-, provider-, system-, and health policy-related factors. Patient comorbidity, poor understanding of FIT, anxiety and fear regarding colonoscopy, lack of provider referral for colonoscopy, lack of colonoscopy availability, and scheduling difficulties are associated with low follow-up rates. ${ }^{39,} 40$, 43-46 Federally qualified health centers (FQHC) and other closed-health systems without in-house specialty services have the additional challenge of coordinating care with gastroenterologists outside their health system to obtain colonoscopies for patients with abnormal FIT. ${ }^{24}$ Current insurance policy also plays a role. Colonoscopies performed after an abnormal FIT are considered diagnostic rather than a covered preventive service, and patients may be required to pay a copayment. ${ }^{47}$

Interventions to address these barriers and increase colonoscopic follow-up are understudied but have included patient and provider education, mailed and electronic provider and patient reminders, systems to track abnormal FIT results, and patient navigation to increase throughput to colonoscopy. ${ }^{48}$ One challenge is that health systems are not currently held accountable for measuring or reporting how often patients with abnormal stool-based screening results undergo colonoscopy. As the screening process is not complete until those with abnormal results undergo diagnostic testing, there should be movement nationally towards requiring health systems to report screening completion rates. Compulsory reporting of colonoscopy follow-up rates, as is done for CRC screening rates through the Healthcare Effectiveness Data and Information Set (HEDIS), will signal to health centers the need for increased attention to abnormal screening results. 


\section{Time to Colonoscopy After Abnormal FIT Matters}

Until relatively recently, we knew very little about the time interval between an abnormal FIT and diagnostic colonoscopy that is associated with poor outcomes. Prior studies used somewhat arbitrary intervals of 6 or 12 months to define colonoscopy completion endpoints. ${ }^{49}$ New data, however, suggest an increased risk for CRC only when colonoscopy is delayed 10 to 12 months or more after abnormal FIT (OR $1.48,95 \% \mathrm{CI} 1.05-2.08) .{ }^{38} \mathrm{~A}$ microsimulation study to estimate the impact of delays to FIT follow-up in an average-risk population also supports increased mortality and decreased cost-effectiveness of screening when follow-up is delayed beyond 12 months. ${ }^{50}$ While the timing of colonoscopy may not be as urgent as previously considered, we must balance this knowledge with what is known about patient behavior around colonoscopy. Patients that have not completed colonoscopy within 6 months of an abnormal FIT are unlikely to ever complete the diagnostic evaluation in the absence of outreach. ${ }^{51}$ As we continue to investigate the optimal time to colonoscopy, it is most prudent for health systems to encourage patients and providers to complete colonoscopy as soon as possible and definitely within 10 months. ${ }^{38}$

\section{A Focus on Repeat Screening: Improving Adherence to FIT Screening}

Organized FIT screening programs depend on adherence to recurrent FIT to reduce CRC incidence and mortality. FIT sensitivity is highest in the first round of screening (84.5\%) and can detect an additional $75 \%$ of CRC cases with each subsequent year of testing. ${ }^{52}$ The USPSTF recommends an annual approach while the American College of Physicians (ACP) recommends biennial exams; however, randomized controlled trials are underway to compare these two approaches. $^{7,8,53,54}$

While annual FIT is commonly prescribed, adherence is often suboptimal. Studies evaluating adherence over multiple rounds of yearly screening demonstrate less than $50 \%$ compliance. ${ }^{55-58}$ Adherence appears to improve with implementation of clinical reminders for patients and providers, coupling FIT screening with other annual preventative health screenings like influenza vaccination, and automated orders for screening tests. ${ }^{59-61}$ Health systems should assess FIT adherence rates over time to maximize FIT effectiveness and consider strategies to encourage repeat testing among patients and providers when participation is low.

\section{Future Directions in FIT Programs for Improving CRC Outcomes}

The introduction of CRC screening in the U.S. accounts for up to $50 \%$ of the decline in CRC incidence and mortality over the past four decades. ${ }^{62,}{ }^{63}$ FIT is a staple of many health system screening programs, offering a convenient and inexpensive strategy to increase patient participation in screening and overall CRC screening rates. ${ }^{64,}{ }^{65}$ However, as we have emphasized, screening by FIT is a multistep process and is complicated by several factors, including choice of FIT kit, appropriate FIT kit administration and use, timely diagnostic follow-up after abnormal FIT, and adherence to annual or biennial FIT screening over time.

Inappropriate use of FIT is a clinical challenge that places patients at risk for poor outcomes. ${ }^{10,36,39}$ Maximizing the effectiveness of FIT screening programs mandates attention from health systems, health professionals, patients, researchers, quality officers, and policy leaders. Health care systems must be mindful of FIT performance characteristics and colonoscopy availability when selecting the appropriate FIT kit for their setting. Furthermore, health care systems must develop mechanisms for measuring and monitoring colonoscopy rates after abnormal FIT. Innovations in informatics technology and EHRs may help automate and optimize how we measure and monitor screening and follow-up rates, which will facilitate the introduction and evaluation of interventions. Researchers and quality improvement leaders can then guide the implementation and evaluation of interventions to achieve quality benchmarks for FIT processes, increase colonoscopic follow-up after abnormal FIT, and improve long-term adherence to FIT. Effective strategies to accomplish these goals, including electronic tracking of patients with abnormal FIT results, provider reminders to order colonoscopy, patient reminders, and patient navigation, should be considered and tailored to the clinical setting. ${ }^{48,}{ }^{66}$ In addition to these efforts, providers and patients must engage in informed shared decision making about appropriate use of FIT to achieve high participation in screening and diagnostic follow-up when needed. Provider education about appropriate and inappropriate use of FIT may help in this capacity. ${ }^{22,}{ }^{66}$ Emphasis must also be placed on policy to improve insurance coverage for and reporting of diagnostic follow-up after abnormal results. With a concerted effort to optimize these critical components of FIT screening, we can make greater strides towards the elimination of CRC and gain progress towards making FIT count.

Acknowledgments: The authors would like to thank Dr. James Allison and Edgar Corona for their assistance in reviewing the manuscript.

Corresponding Author: Folasade P. May, MD, PhD, MPhil; Department of Medicine, VA Greater Los Angeles Healthcare System, CA, Los Angeles, USA (e-mail: fmay@mednet.ucla.edu).

\section{Compliance with Ethical Standards:}

Conflict of Interest: The authors declare that they do not have a conflict of interest.

\section{REFERENCES}

1. Siegel RL, Miller KD, Jemal A. Cancer statistics, 2015. CA: a cancer journal for clinicians. 2015;65(1):5-29. https://doi.org/10.3322/caac. 21254 
2. Noone A, Howlader N, Krapcho M, Miller D, Brest A, Yu M, et al.SEER Cancer Statistics Review 1975-2015. National Cancer Institute, Bethesda, MD.

3. Yang DX, Gross CP, Soulos PR, Yu JB. Estimating the magnitude of colorectal cancers prevented during the era of screening: 1976 to 2009 . Cancer 2014;120(18):2893-901. https://doi.org/10.1002/cncr.28794

4. Naishadham D, Lansdorp-Vogelaar I, Siegel R, Cokkinides V, Jemal A. State disparities in colorectal cancer mortality patterns in the United States. Cancer epidemiology, biomarkers \& prevention : a publication of the American Association for Cancer Research, cosponsored by the American Society of Preventive Oncology. 2011;20(7):1296-302. https://doi.org/10.1158/1055-9965.epi-11-0250

5. ACS. American Cancer Society: Colorectal Cancer Facts \& Figures 20172019. Atlanta: American Cancer Society. Available at: https://www. cancer.org/content/dam/cancer-org/research/cancer-facts-and-statistics/colorectal-cancer-facts-and-figures/colorectal-cancer-facts-and-figures-2017-2019.pdf. Accessed 20 Feb 2019.

6. National Center for Health Statistics. NHIS data, questionnaires and related documentation. Available at: https://www.cdc.gov/nchs/nhis/ data-questionnaires-documentation.htm. Accessed 1 Mar 2019.

7. Bibbins-Domingo K, Grossman DC, Curry SJ, Davidson KW, Epling JW, Jr., Garcia FAR, et al. Screening for Colorectal Cancer: US Preventive Services Task Force Recommendation Statement. JAMA 2016;315(23):2564-75. https://doi.org/10.1001/jama.2016.5989

8. Gaseem A, Crandall CJ, Mustafa RA, Hicks LA, Wilt TJ, Physicians $\mathrm{ftCGCotACo.} \mathrm{Screening} \mathrm{for} \mathrm{Colorectal} \mathrm{Cancer} \mathrm{in} \mathrm{Asymptomatic} \mathrm{Average-}$ Risk Adults: A Guidance Statement From the American College of Physicians. Annals of internal medicine. 2019;171(9):643-54. https:// doi.org/10.7326/m19-0642

9. Rex DK, Boland CR, Dominitz JA, Giardiello FM, Johnson DA, Kaltenbach T, et al. Colorectal Cancer Screening: Recommendations for Physicians and Patients from the U.S. Multi-Society Task Force on Colorectal Cancer. Am J Gastroenterol. 2017;112(7):1016-30. https:// doi.org/10.1038/ajg.2017.174

10. Robertson DJ, Lee JK, Boland CR, Dominitz JA, Giardiello FM, Johnson DA, et al. Recommendations on Fecal Immunochemical Testing to Screen for Colorectal Neoplasia: A Consensus Statement by the US Multi-Society Task Force on Colorectal Cancer. Gastroenterology. 2017;152(5):121737.e3. https://doi.org/10.1053/j.gastro.2016.08.053

11. DeBourcy AC, Lichtenberger S, Felton S, Butterfield KT, Ahnen DJ, Denberg TD. Community-based preferences for stool cards versus colonoscopy in colorectal cancer screening. Journal of general internal medicine. 2008;23(2):169-74. https://doi.org/10.1007/s11606-0070480-1

12. Quintero E, Castells A, Bujanda L, Cubiella J, Salas D, Lanas A, et al. Colonoscopy versus fecal immunochemical testing in colorectal-cancer screening. The New England journal of medicine. 2012;366(8):697-706. https://doi.org/10.1056/NEJMoa1108895

13. Hundt $\mathrm{S}$, Haug U, Brenner H. Comparative evaluation of immunochemical fecal occult blood tests for colorectal adenoma detection. Annals of internal medicine. 2009;150(3): 162-9.

14. Levy BT, Bay C, Xu Y, Daly JM, Bergus G, Dunkelberg J, et al. Test Characteristics of Faecal Immunochemical Tests (FIT) Compared with Optical Colonoscopy. Journal of Medical Screening. 2014;21(3):133-43. https://doi.org/10.1177/0969141314541109

15. Lee JK, Liles EG, Bent S, Levin TR, Corley DA. Accuracy of fecal immunochemical tests for colorectal cancer: systematic review and meta-analysis. Annals of internal medicine. 2014;160(3):171. https:// doi.org/10.7326/m13-1484

16. Goede SL, van Roon AH, Reijerink JC, van Vuuren AJ, Lansdorp-Vogelaar I, Habbema JD, et al. Cost-effectiveness of one versus two sample faecal immunochemical testing for colorectal cancer screening. Gut. 2013;62(5):727-34. https://doi.org/10.1136/gutjnl-2011-301917

17. Navarro M, Nicolas A, Ferrandez A, Lanas A. Colorectal cancer population screening programs worldwide in 2016: An update. World journal of gastroenterology. 2017;23(20):3632-42. https://doi.org/10.3748/wjg. v23.i20.3632

18. van Rijn AF, Stroobants AK, Deutekom M, Lauppe C, Sturk A, Bossuyt $\mathrm{PM}$, et al. Inappropriate use of the faecal occult blood test in a university hospital in the Netherlands. European journal of gastroenterology \& hepatology. 2012;24(11):1266-9. https://doi.org/10.1097/MEG. Ob013e328313bbd3

19. Aniwan S, Ratanachu Ek T, Pongprasobchai S, Limsrivilai J, Praisontarangkul OA, Pisespongsa P, et al. The Optimal Cut-Off Level of The Fecal Immunochemical Test For Colorectal Cancer Screening in a Country with Limited Colonoscopy Resources: A Multi-Center Study from Thailand. Asian Pacific journal of cancer prevention : APJCP. 2017;18(2):405-12. https://doi.org/10.22034/apjcp.2017.18.2.405

20. van Rossum LG, van Rijn AF, Laheij RJ, van Oijen MG, Fockens P, Jansen $\mathrm{JB}$, et al. Cutoff value determines the performance of a semi-quantitative immunochemical faecal occult blood test in a colorectal cancer screening programme. British journal of cancer. 2009;101(8): 1274-81. https://doi. org/10.1038/sj.bjc.6605326

21. Kahi CJ, Myers LJ, Slaven JE, Haggstrom D, Pohl H, Robertson DJ, et al. Lower endoscopy reduces colorectal cancer incidence in older individuals. Gastroenterology. 2014;146(3):718-25 e3. https://doi.org/10.1053/j. gastro.2013.11.050

22. Carlson CM, Kirby KA, Casadei MA, Partin MR, Kistler CE, Walter LC. Lack of follow-up after fecal occult blood testing in older adults: Inappropriate screening or failure to follow up? Archives of Internal Medicine. 2011;171(3):249-56. https://doi.org/10.1001/archinternmed. 2010.372

23. Brenner H, Tao S. Superior diagnostic performance of faecal immunochemical tests for haemoglobin in a head-to-head comparison with guaiac based faecal occult blood test among 2235 participants of screening colonoscopy. European journal of cancer (Oxford, England : 1990). 2013;49(14):3049-54. https://doi.org/10.1016/j.ejca.2013.04. 023

24. Daly JM, Levy BT, Moss CA, Bay CP. System Strategies for Colorectal Cancer Screening at Federally Qualified Health Centers. American journal of public health. 2015;105(1):212-9. https://doi.org/10.2105/ ajph.2013.301790

25. Chiang TH, Chuang SL, Chen SL, Chiu HM, Yen AM, Chiu SY, et al. Difference in performance of fecal immunochemical tests with the same hemoglobin cutoff concentration in a nationwide colorectal cancer screening program. Gastroenterology. 2014;147(6):1317-26. https:// doi.org/10.1053/j.gastro.2014.08.043

26. Zubero MB, Arana-Arri E, Pijoan JI, Portillo I, Idigoras I, Lopez-Urrutia A, et al. Population-based colorectal cancer screening: comparison of two fecal occult blood test. Frontiers in pharmacology. 2014;4:175. https:// doi.org/10.3389/fphar.2013.00175

27. Oluloro A, Petrik AF, Turner A, Kapka T, Rivelli J, Carney PA, et al. Timeliness of Colonoscopy After Abnormal Fecal Test Results in a Safety Net Practice. Journal of community health. 2016;41(4):864-70. https:// doi.org/10.1007/s10900-016-0165-y

28. Lin JS, Piper MA, Perdue LA, et al. Screening for colorectal cancer: Updated evidence report and systematic review for the us preventive services task force. Jama. 2016;315(23):2576-94. https://doi.org/10. 1001/jama.2016.3332

29. Shapiro JA, Bobo JK, Church TR, Rex DK, Chovnick G, Thompson TD, et al. A Comparison of Fecal Immunochemical and High-Sensitivity Guaiac Tests for Colorectal Cancer Screening. Am J Gastroenterol. 2017;112(11):1728-35. https://doi.org/10.1038/ajg.2017.285

30. Efficacy of Fecal Immunochemical Test Using Digital Rectal Exam (FITDRE). National Library of Medicine (U.S.), ClinicalTrials.gov. 2017. https://clinicaltrials.gov/ct2/show/NCT03013855. Accessed 1 Mar 2019.

31. van Roon AH, Hol L, van Vuuren AJ, Francke J, Ouwendijk M, Heijens A, et al. Are fecal immunochemical test characteristics influenced by sample return time? A population-based colorectal cancer screening trial. Am J Gastroenterol. 2012;107(1):99-107. https://doi.org/10.1038/ajg.2011. 396

32. Doubeni CA, Jensen CD, Fedewa SA, Quinn VP, Zauber AG, Schottinger JE, et al. Fecal Immunochemical Test (FIT) for Colon Cancer Screening: Variable Performance with Ambient Temperature. Journal of the American Board of Family Medicine : JABFM. 2016;29(6):672-81. https://doi. org/10.3122/jabfm.2016.06.160060

33. Coronado GD, Petrik AF, Vollmer WM, Taplin SH, Keast EM, Fields S, et al. Effectiveness of a Mailed Colorectal Cancer Screening Outreach Program in Community Health Clinics: The STOP CRC Cluster Randomized Clinical Trial. JAMA Intern Med. 2018;178(9):1174-81. https://doi. org/10.1001/jamainternmed.2018.3629

34. Grobbee EJ, Wieten E, Hansen BE, Stoop EM, de Wijkerslooth TR, Lansdorp-Vogelaar I, et al. Fecal immunochemical test-based colorectal cancer screening: The gender dilemma. United European gastroenterology journal. 2017;5(3):448-54. https://doi.org/10.1177/ 2050640616659998

35. Kim NH, Jung YS, Lim JW, Park JH, Park DI, Sohn CI. Yield of repeat colonoscopy in asymptomatic individuals with a positive fecal immunochemical test and recent colonoscopy. Gastrointestinal endoscopy. 2019. https://doi.org/10.1016/j.gie.2019.01.012 
36. Lee YC, Li-Sheng Chen S, Ming-Fang Yen A, Yueh-Hsia Chiu S, ChingYuan Fann J, Chuang SL, et al. Association Between Colorectal Cancer Mortality and Gradient Fecal Hemoglobin Concentration in Colonoscopy Noncompliers. Journal of the National Cancer Institute. 2017;109(5). https://doi.org/10.1093/jnci/djw269

37. Flugelman AA, Stein N, Segol O, Lavi I, Keinan-Boker L. Delayed Colonoscopy Following a Positive Fecal Test Result and Cancer Mortality. JNCI Cancer Spectr. 2019;3(2):pkz024. https://doi.org/10.1093/jncics/ pkz024

38. Corley DA, Jensen CD, Quinn VP, Doubeni CA, Zauber AG, Lee JK, et al Association Between Time to Colonoscopy After a Positive Fecal Test Result and Risk of Colorectal Cancer and Cancer Stage at Diagnosis Jama. 2017;317(16):1631-41. https://doi.org/10.1001/jama.2017. 3634

39. Heavener T, Jaeger V, Stephenson K, McStay F, Sing T. Diagnostic colonoscopy following abnormal FIT results: A quality improvemen analysis. Journal of Clinical Oncology. 2018;36(4_suppl):568-. https:// doi.org/10.1200/JCO.2018.36.4_suppl.568

40. Issaka RB, Singh MH, Oshima SM, Laleau VJ, Rachocki CD, Chen EH, et al. Inadequate Utilization of Diagnostic Colonoscopy Following Abnormal FIT Results in an Integrated Safety-Net System. The American Journal Of Gastroenterology. 2016;112:375. https://doi.org/10.1038/ ajg.2016.555.

41. Llovet D, Serenity M, Conn LG, Bravo CA, McCurdy BR, Dube C, et al. Reasons For Lack of Follow-up Colonoscopy Among Persons With A Positive Fecal Occult Blood Test Result: A Qualitative Study. Am J Gastroenterol. 2018. https://doi.org/10.1038/s41395-018-0381-4

42. Martin J, Halm EA, Tiro JA, Merchant Z, Balasubramanian BA, McCallister K, et al. Reasons for Lack of Diagnostic Colonoscopy After Positive Result on Fecal Immunochemical Test in a Safety-Net Health System. The American journal of medicine. 2017;130(1):93.e1-e7. https://doi.org/10.1016/j.amjmed.2016.07.028

43. May F, Yano EM, Provenzale D, Brunner J, Yu C, Phan J, et al. Barriers to Follow-Up Colonoscopies for Patients With Positive Results From Fecal Immunochemical Tests During Colorectal Cancer Screening. Clinical gastroenterology and hepatology : the official clinical practice journal of the American Gastroenterological Association. 2018. https://doi.org/10. 1016/j.cgh.2018.05.022

44. Rao SK, Schilling TF, Sequist TD. Challenges in the management of positive fecal occult blood tests. Journal of general internal medicine. 2009;24(3):356-60. https://doi.org/10.1007/s11606-008-0893-5

45. Fisher DA, Jeffreys A, Coffman CJ, Fasanella K. Barriers to full colon evaluation for a positive fecal occult blood test. Cancer epidemiology, biomarkers \& prevention : a publication of the American Association for Cancer Research, cosponsored by the American Society of Preventive Oncology. 2006;15(6):1232-5. https://doi.org/10.1158/1055-9965.epi05-0916

46. Partin MR, Gravely AA, Burgess JF, Jr., Haggstrom DA, Lillie SE, Nelson $\mathrm{DB}$, et al. Contribution of patient, physician, and environmental factors to demographic and health variation in colonoscopy follow-up for abnormal colorectal cancer screening test results. Cancer. 2017;123(18):3502-12. https://doi.org/10.1002/cncr.30765

47. National Colorectal Cancer Roundtable. Coverage of Colonoscopies Under the Affordable Care Act's Prevention Benefit. Available at: http://nccrt org/wp-content/uploads/NCCRT.KFF-report.pdf. Accessed 20 Feb 2019 .

48. Selby K, Baumgartner C, Levin TR, Doubeni CA, Zauber AG, Schottinger $\mathrm{J}$, et al. Interventions to Improve Follow-up of Positive Results on Fecal Blood Tests: A Systematic Review. Annals of internal medicine. 2017;167(8):565-75. https://doi.org/10.7326/m17-1361

49. Department of Veterans Affairs Office of Inspector General. Evaluation of Colorectal Cancer Screening and Follow-Up in Veterans Health Administration Facilities. Available at: https://www.va.gov/oig/pubs/VAOIG-1301741-215.pdf. Accessed 20 Feb 2019.

50. Meester RG, Zauber AG, Doubeni CA, Jensen CD, Quinn VP, Helfand M, et al. Consequences of Increasing Time to Colonoscopy Examination After Positive Result From Fecal Colorectal Cancer Screening Test. Clinical gastroenterology and hepatology : the official clinical practice journal of the American Gastroenterological Association. 2016;14(10): 1445-51.e8. https://doi.org/10.1016/j.cgh.2016.05.017

51. Chubak J, Garcia MP, Burnett-Hartman AN, Zheng Y, Corley DA, Halm EA, et al. Time to Colonoscopy after Positive Fecal Blood Test in Four U.S. Health Care Systems. Cancer Epidemiol Biomarkers Prev. 2016;25(2):344-50. https://doi.org/10.1158/1055-9965.EPI-15-0470
52. Jensen CD, Corley DA, Quinn VP, Doubeni CA, Zauber AG, Lee JK, et al. Fecal Immunochemical Test Program Performance Over 4 Rounds of Annual Screening: A Retrospective Cohort Study. Annals of internal medicine. 2016;164(7):456-63. https://doi.org/10.7326/m15-0983

53. Dominitz JA, Robertson DJ, Ahnen DJ, Allison JE, Antonelli M, Boardman KD, et al. Colonoscopy vs. Fecal Immunochemical Test in Reducing Mortality From Colorectal Cancer (CONFIRM): Rationale for Study Design. Am J Gastroenterol. 2017;112(11):1736-46. https://doi. org/10.1038/ajg.2017.286

54. Colonoscopy and FIT as Colorectal Cancer Screening Test in the Average Risk Population [NCT02078804]. ClinicalTrails.gov, https://www. clinicaltrials.gov/ct2/show/NCT02078804. Accessed March 9, 2019.

55. Crotta S, Segnan N, Paganin S, Dagnes B, Rosset R, Senore C. High rate of advanced adenoma detection in 4 rounds of colorectal cancer screening with the fecal immunochemical test. Clinical gastroenterology and hepatology : the official clinical practice journal of the American Gastroenterological Association. 2012;10(6):633-8. https://doi.org/10. 1016/j.cgh.2012.02.030

56. van der Vlugt M, Grobbee EJ, Bossuyt PM, Bongers E, Spijker W, Kuipers $\mathrm{EJ}$, et al. Adherence to colorectal cancer screening: four rounds of faecal immunochemical test-based screening. British journal of cancer. 2017;116(1):44-9. https://doi.org/10.1038/bjc.2016.399

57. Parente F, Boemo C, Ardizzoia A, Costa M, Carzaniga P, Ilardo A, et al. Outcomes and cost evaluation of the first two rounds of a colorectal cancer screening program based on immunochemical fecal occult blood test in northern Italy. Endoscopy. 2013;45(1):27-34. https://doi.org/10. 1055/s-0032-1325800

58. Singal AG, Corley DA, Kamineni A, Garcia M, Zheng Y, Doria-Rose PV, et al. Patterns and predictors of repeat fecal immunochemical and occult blood test screening in four large health care systems in the United States. Am J Gastroenterol. 2018;113(5):746-54. https://doi.org/10. 1038/s41395-018-0023-x

59. Potter MB, Somkin CP, Ackerson LM, Gomez V, Dao T, Horberg MA, et al. The FLU-FIT program: an effective colorectal cancer screening program for high volume flu shot clinics. The American journal of managed care. 2011;17(8):577-83.

60. Green BB, Anderson ML, Chubak J, Fuller S, Meenan RT, Vernon SW Impact of continued mailed fecal tests in the patient-centered medical home: Year 3 of the Systems of Support to Increase Colon Cancer Screening and Follow-Up randomized trial. Cancer. 2016;122(2):312-21. https://doi.org/10.1002/cncr.29734

61. Baker DW, Brown T, Goldman SN, Liss DT, Kollar S, Balsley K, et al. Twoyear follow-up of the effectiveness of a multifaceted intervention to improve adherence to annual colorectal cancer screening in community health centers. Cancer causes \& control : CCC. 2015;26(11):1685-90. https://doi.org/10.1007/s10552-015-0650-0

62. Zauber AG. The impact of screening on colorectal cancer mortality and incidence: has it really made a difference? Digestive diseases and sciences. 2015;60(3):681-91. https://doi.org/10.1007/s10620-0153600-5

63. Shaukat A, Mongin SJ, Geisser MS, Lederle FA, Bond JH, Mandel JS, et al. Long-term mortality after screening for colorectal cancer. The New England journal of medicine. 2013;369(12):1106-14. https://doi.org/10. 1056/NEJMoa1300720

64. Inadomi JM, Vijan S, Janz NK, Fagerlin A, Thomas JP, Lin YV, et al. Adherence to colorectal cancer screening: a randomized clinical trial of competing strategies. Arch Intern Med. 2012;172(7):575-82. https://doi. org/10.1001/archinternmed.2012.332

65. Yu C, Skootsky S, Grossman M, Garner OB, Betlachin A, Esrailian E, et al. A Multi-Level Fit-Based Quality Improvement Initiative to Improve Colorectal Cancer Screening in a Managed Care Population. Clinical and translational gastroenterology. 2018;9(8):177. https://doi.org/10.1038/ s41424-018-0046-Z

66. Selby K, Jensen CD, Zhao WK, Lee JK, Slam A, Schottinger JE, et al Strategies to Improve Follow-up After Positive Fecal Immunochemical Tests in a Community-Based Setting: A Mixed-Methods Study. Clinical and translational gastroenterology. 2019;10(2):e00010. https://doi.org/ $10.14309 /$ ctg. 0000000000000010

Publisher's Note Springer Nature remains neutral with regard to jurisdictional claims in published maps and institutional affiliations. 